\title{
A Proposal of the Model of International Marketing Research as Information Basis in Game Theory
}

\author{
Vedran Stanetić ${ }^{1 *}$ \\ ${ }^{1}$ Supreme Office for the Republic of Srpska Public Sector Auditing, financial auditing, Banja Luka, Republic of Srpska, \\ $\mathrm{BiH}$
}

\begin{abstract}
Analyzing the theory of games it can be noticed that the moves and strategy of the players are not sufficiently based on the relevant information. Most often, the only information that game strategy methodologists advocate is rationality, which certainly does not have to be the case in all games. In addition, the greater practical representation of game theory is avoided by the numerous assumptions and limitations set by the particular model of a particular game, and whose practical foundation does not always have to be realistic.

An interdisciplinary combination of international marketing research and game theory would create a new quality for one and the other discipline. However, the biggest benefit would be for business or marketing decision makers, especially in industrial marketing. The aim of the paper is to present a new model that, in conditions of globalized business, will provide information support from the international market for business decision making using the theory of games. The proposed model is in the form of an information system for international marketing research in support of business decision-making.

The first part of the paper is devoted to the analysis of game theory, in particular the analysis of assumptions and limitations for its greater practical application. A model that would partially overcome the described problems is proposed in the second part of the paper. The methodology used in the paper is also characteristic of marketing research and game theory.
\end{abstract}

Key words: information, international marketing research, rational behavior, game theory

JEL Classification: C79, D83, M39

\section{INTRODUCTION}

The determination of the methodologists of the game theory for theoretical development or its application in laboratory conditions has resulted in not quite an enviable level of its practical usability when solving the problems that are faced by business or marketing decision makers. Game theory deals exclusively with rational behavior of players and predictable decisions. If there are deviations from rational behavior, such deviations should be easily explained. That's why much of game theory appears sterile to the marketing scientist (Chatterjee, Lilien, 1986, p. 90). Marketing exists to control consumer behaviour, which is usually irrational and affected by many different, often unidentifiable factors - such as feelings and desires - which can't be predicted or quantified (Chowdrey, 2014).

The characteristic of modern business is a very dynamic and wide environment where the game theory models are usually not adapted for. Some of the characteristics of the current

*E-mail: staneticv@yahoo.com 
business are: large and sudden changes in the environment and working conditions; a large amount of diverse data; information and knowledge as the most valuable resource; unpredictable competitive influences from the farthest parts of the world, consumer penetration and the like. The world is rapidly globalizing and this is providing many opportunities and major challenges to the nations and people of the world (Salvatore, 2013, p. 1). We are witnessing the phenomenon of close integration of countries and peoples of the world (Peng, 2011, p. 16) which is shortly called globalization.

The cultural characteristics of some nations, the psychological circumstances of the decisionmakers, the context in which the game is located, etc. can classically described behavior of homo oeconomicus in a game and conditions of globalized business make irrational and vice versa. Some games in game theory are designed as individual, independent and isolated, and today's business, as briefly described, has exactly the opposite characteristics. When added to this, information based on information from the local environment, without considering problems in a global context and without an organized information flow from the international market, would not be sufficient to ensure full information coverage, gaining a sense of seriousness and the size of the problem.

However, this should in no way mean the rejection of further attempts to apply the game theory as a valuable tool in business or marketing decision-making in the future. The reason why game theory has not so far been represented in marketing is not because it can not be applied, but only because it is very challenging (Chowdrey, 2014).

This paper will show how an interdisciplinary approach to the problem described can provide an appropriate solution to the problem. The proposal of the solution of the problem was given in the form of the model of international marketing research as information basis in game theory. As international marketing research is a discipline that is very broad and comprehensive, the model proposal is concretized in the form of an international marketing information system. The advantage of such an approach in marketing research is its analyticity and the convenience of programming - at least some parts of such a model. On the other hand, the lack is sometimes too formalized and slow conduction of research.

This paper presents a combination of the most important principles and ideas on which international marketing and international marketing research, game theory and information systems are based and aimed at solving the problem described. In the available literature, which was available to the author, no papers were found suggesting a similar solution to the problem described.

\section{GENERAL THEORETICAL ASSUMPTIONS OF GAME THEORY}

\section{Strategic decision making using models of game theory}

The two basic assumptions in game theory are:

1. Players participating in the game try to behave rationally, i.e. they strive to achieve maximum profit at a given moment (i.e., selfish players), and

2. Players decide strategically, i.e. making decisions they take into account decisions of other players.

Game theory, by its definition, should focus on rational strategic decision-making. In order to behave rationally, players must have a predetermined payment function (material benefit) that they will behave and decide on. Since these are strategic decisions, players do not know the final decision of other players before they make their own decision. Based on the above, it can be concluded that the players can realize or do not realize material benefit solely based on the chosen own way of action, as well as the actions of other players. 
In theory, there are at least five possible concepts equilibrium in any game. These are the following concepts:

1. Maxmin and minmax,

2. Social welfare,

3. Pareto optimal concept,

4. The concept of iterative domination and

5. Nesh equilibrium.

The goal of each of these concepts is the same: coming to equilibrium. However, the ways of achieving this goal are different.

At the beginning it would be good to point out the definition of equilibrium because the notion of equilibrium in game theory is not identical to the notion of equilibrium in the economy generally. The equilibrium $s^{*}=\left(s_{1}{ }^{*} \ldots s_{\mathrm{n}}{ }^{*}\right)$ is a strategy profile consisting of a best strategy for each of the $n$ players in the game (Rasmusen, 2006, p. 18). In game theory equilibrium is a strategic profile, while in the economy equilibrium would be the outcome of this strategic profile.

The maxmin concept is recognizable in that the player-striker strives to maximize his winnings, i.e. to choose the highest of all the minimum wins (the maximum minimum amount an attacker can achieve). On the other hand, the player-defence must sacrifice a certain amount. The player-defender will try to minimize his losses, or from the maximum payouts for each bet, he chooses the one for which the payoff is minimal. Where the values of the maximum of all the minimum strikes of the striker and the minimum of all the maximum defenses of the defender are matched, there is a solution of the game (maxmin $=$ minmax). Realizing this concept for one of the players would not be a problem to predict the outcome of the game, provided that it anticipates the actions of another or other players. Reasoning on the basis of the minmax of choice, in a way, really works conservatively. The more you suppose that your opponent knows your move in advance, and then devises his best reaction, the minmax becomes more attractive. If we imagine that some of them are the first to choose the row, then his opponent chooses the field in that row, the maxmin would have a perfect sense. On the other hand, if both players are uncertain of what will happen and can not determine the probability, they will surely choose other strategies. If both players gamble this way, we can not predict the outcome of the game (Gaus, 2012, p. 116).

The concept of social welfare represents forms of games in which society is mutually opposed to individuals in order to preserve or establish social values. Individuals often pretend to some public good in order to achieve personal benefits. In situations where personal benefits for individuals mean the reduction of social well-being, and vice versa, a relevant concept is described as social welfare. Examples are: construction of infrastructures, pollution, water resources, social organization, etc. As in such situations does not exist mechanism that would bring players into equal negotiating positions, this concept is not representative of the market conditions or business, so the analysis of information needs in those cases is not expressed.

The concept of Pareto efficiency implies that resources are fully utilized. This means that there is no possibility of improving the position of one of the players, except for the resources that someone else already uses. In the Pareto optimal concept, some of the players can not improve their position, and as a consequence, do not harm another player. For the economy to be Pareto efficient, it must meet the conditions of exchange efficiency, production efficiency, and product-mix efficiency (Stiglitz and Walsh, 2006, p. 222). The listed conditions can only be met in a competitive market.

The concept of iterative domination is based on the principle of domination of some strategy for one of the players because this strategy brings more or equal benefit than any other strategy of other players. Some strategies will simply never be used, because there are always others that 
are better for the player being watched. In the case of a strategy of iterative domination, information about planned player actions, similar to the maxmin concept, is very valuable.

In the Nash equilibrium concept, each player follows his strategy of maximizing possible winnings assuming that other players do the same. This strategy is best represented by Theorem 1: (Webb, 2007, p. 72)

Suppose there exists a pair of pure strategies $\left(s_{1}^{*}, s_{2}^{*}\right)$ such that

$$
\begin{aligned}
& \pi_{1}\left(s_{1}^{*}, s_{2}^{*}\right) \geq \pi_{1}\left(s_{1}, s_{2}^{*}\right) \forall s_{1} \in S_{1} \\
& \text { and } \pi_{2}\left(s_{1}^{*}, s_{2}^{*}\right) \geq \pi_{1}\left(s_{1}^{*}, s_{2}\right) \forall s_{2} \in S_{2}
\end{aligned}
$$

Than $\left(\mathrm{s}_{1}{ }^{*}, \mathrm{~s}_{2}{ }^{*}\right)$ is a Nash equilibrium.

Unlike the strategy of iterative domination, the Nash equilibrium concept does not start from the probability of choosing each of options available to players, but the outcome of a game that provides the most favorable amount of payouts for each player is sought. The extent to which this strategy is significant in game theory is best confirmed by Theorem 2 - Nash's theorem of 1950: (Gibbons, 1992, p. 45)

In the n-player normal-form game $G=\left\{S_{1}, \ldots, S_{n} ; u_{1}, \ldots, u_{n}\right\}$, if $n$ is finite and $\mathrm{Si}$ is finite for every $i$ then there exists at least one Nash equilibrium, possibly involving mixed strategies.

In some cases it is possible that in one game there are two or even more Nash equilibrium. It is a question how will players then decide and how they will choose the right equilibrium. Pareto optimum Nash equilibrium at first glance should be preferred by every player. However, this does not always have to be the case. Therefore, the theorist of game theory introduced in the analysis the concept of the improved Nash equilibrium (Gints, 1999, p. 103).

Different concepts of approach to equilibrium give different solutions (equilibriums). In addition, it is often not easy to determine which solution is the best, because the solution often depends on the type of game, how players interpret the winnings from the payment matrix, and so on. The situation is further complicated in the event of a greater number or lack of balance. Clearly, this makes it difficult to apply game theory.

The assumption that all players know their own utility function is important but also difficult to prove. It is true that players in one game have not only one but more of their utility functions. Often, these utility functions are not clearly separated. In accordance with the development of the game, some utility functions become more dominant than others. Due to the frequent interconnection of multiple players' games, their own utility functions are changing. The assumption that all players know the actual choice of action for each player in simple games is real. However, as games in practical conflicts of players are mostly complex, without an appropriate mechanism for collecting and processing data and reporting on observed actions of other players this assumption is not real.

Assumption that each player knows that each player knows etc. the utility function of each player, similar to the above, without the appropriate mechanism for collecting and processing data and reporting on the useful function in complex games is not realistic. The utility function of each player is not easily noticeable; they are not easily measurable and are not unchanged, even in simple games. Assumption that every player $i$ knows that his rival $j$ has some belief about player $i$ moves given with some probability $p$ without a proper mechanism for collecting and processing data and reporting on rival beliefs remains a clear assumption - not about probabilities but about the assumption itself. How to believe in the assumption that a rival has a probability of a player's planned moves when there is no evidence that he has any knowledge about planned moves of any player.

It should be kept in mind that during the theoretical setting and the elaboration of the previously presented concepts of approach to equilibrium in the game theory, it did not take into 
account their application solely in the economy. The game theory is most often seen as a field of mathematics. In game theory analysts almost always starts with assumption that the payment matrix is predetermined and equally known to each player - an assumption that is hardly realistic. Also, relying on the principle of insufficient reason (Gints, 1999, p. 103) and the like.

As can be seen from the previous analysis, there is no concept in game theory which predict the possibility of acting solely after consideration of all available information and anticipate further steps on the basis of that information. Even if information about the previous and immediate effects of other players in the model is considered, there is no guarantee that the information is the last, that they are fully accurate and timely, as there is no complete information about the most probable actions of competitors as response to the actions taken by the players (reactions of competitors).

There is no any concept in game theory that involves the process of collecting and processing data and information, particularly not in an organized and arranged form. Far from the fact that some of the concepts have a model of constant observation of an environment; environment in which the actions of other players are only some of many information (there is no evidence that action of some payer comes as a response solely to the actions of the other players). The previously discussed concepts do not have a built-in mechanism of flexibility so much needed in economic science.

Business decision-making without proper information base and without the possibility of flexible adaptation to changes in the environment could not be characterized as strategic and planned. The previously stated assumption that in the game theory players decide strategically could not satisfy the definition of strategic business or marketing decision-making. From the foregoing, one might conclude that the game theory in fact is not an appropriate tool in the hands of strategists.

Any methodologist of intellectual work and conclusions, as well as almost anyone who tried to make any contribution to scientific or professional thought in any field of science, can distinguish two opposing processes in intellectual work and conclusion: deductive and inductive. For a deductive way of thinking and concluding, it is characteristic that it starts from general principles and goes to individual, while inductive going to the opposite sequence - from individual to general. In the procedure of deductive thinking it is concluded on the basis of the whole, while in inductive thinking the knowledge of the general is based on one or few individual elements that make up whole picture. When it comes to the nature of the relationship between theory and research itself, then the following condition applies: whether theory guides research (known as deductive approach) or whether theory is an outcome of research (known as an inductive approach) (Bryman and Bell, 2003, p. 3). It is obvious that deductive conclusion is more perfect and scientifically acceptable. Mathematics only recognizes deductive conclusions.

However, in natural sciences it is impossible to think and conclude exclusively on the basis of a deductive approach without the application of induction to a certain extent. In mathematics, conclusions are derived from basic, sometimes unsaid, assumptions or conventions (axioms). The same principle applies to the whole deductive approach to conclusion. Sometimes, some assumptions are not entirely scientifically grounded, but are only confirmed as generalizations of relevant experiences. Such generalizations are derived from two basic forms of inductive elements: enumerations and analogies (Stebbing, 1961, p. 249). The enumeration allows for the conclusion of the population based on the characteristics of the sample. Analogy is the conclusion based on belonging to the same or similar class.

Observations should also be added to the inductive elements mentioned above. Since observation is not a scientific method, generalizations based on such a method serve only to corroborate, but not to prove conclusions. However, as the conclusion is sometimes impossible to fully justify on axioms or on deductively proven assumptions, the described generalizations based on observation must enter the process at some point (Rapoport, 1966, p. 147). At the 
same time induction, on the small door, entrances in the process of scientific conclusions and produces conclusions that bear wider knowledge than that given in axioms.

Studying the literature that deals with the field of game theory, the acquired impression is that the game theory is viewed almost exclusively as one of the fields of mathematics. A deductive way of thinking and concluding is the only one relevant to that science field, while for induction there is usually no place. On the other hand, the majority of the academic community, and especially practitioners of strategic thinking in the economy, are aware of the modest application and practical usefulness of game theory. However, as soon as game theory purports to be a prescriptive theory (purports to derive optimal course of action), the inductive component can no longer be dispensed with in application (Rapoport, 1966, p. 147).

The characteristic of strategic business or marketing decision-making and operation is the continuous collection and processing of information and adjustment of direction of movement according to changes in the environment. Observation is an irreplaceable method in this process. The application of induction in game theory, especially for the purposes of strategic business, is a concept that should make a significant contribution to the development of both the scientific field.

\section{Information base in formulating the most likely game}

The analysis below focuses on the information base on planned future actions of other players in the game, as well as to predict what other people guess you will do (Miller, 2003, p. 56). Based on this information a rational player sets the game to maximize its payment function.

Every participant can determine the variables which describe his own actions but not those for other. Nevertheless those 'alien' variables cannot, from its point of view, be described by statistical assumptions. This is because the others are guided, just as he himself, by rational principles - whatever that may mean - and no modus procedendi can be correct which does not attempt to understand those principles and the interactions of conflicting interests of all participants (Von Neumann and Morgenstern, 1953, p. 11).

Also, when two rational individuals have the same information, they must draw the same inferences and come, independently, to the same conclusion (Hargreaves and Varoufakis, 1995, p. 25). Previous claims are known as Harsanyi doctrine (by the theorist John Harsanyi). In the game theory there is no assumption that one of the players is smarter than the other. The initial beliefs of each player are the same, and the only difference is in the type and amount of information among the players.

The goal of the player is to anticipate the actions of other players and as a result the outcome of the game. In real business conditions, beside the knowledge about rationality of players, it is possible to notice a number of other signals or complete information about the intended actions of other players. Such signals, data or information are often not easily available, nor are they systematized, formatted, or verified.

There are three basic categories of the information structure of any game (Geckil and Anderson, 2010, p. 18) :

1. Perfect vs. imperfect information,

2. Complete vs. incomplete information, and

3. Symmetric vs. asymmetric information.

Under perfect information it is understood that at every step of the game of a player who is on the move knows the whole history of the current course of the game. For these games, it is characteristic (but not necessarily) that the players drag the moves sequentially (consecutively). Each player is familiar with the strategies and most likely the moves of any other player and accordingly he acts in the game. The greatest responsibility is on the player who first takes the move, because this move most often determines the further course of the whole game. That 
player has to consider how another player (s) will respond to each of the possible moves of the first player. In these games, some of the players are waiting for their opponent's moves and for each of his moves he has already elaborated an answer. These are games that are rarely met in real business conditions. This is not true for games with non-perfect information. For such games it is characteristic that players act simultaneously, as players do not have the ability to calculate for lack of information.

For the games with complete information, unlike perfect, there is a certain degree of uncertainty in predicting the moves of players involved in the game, as well as the outcome of the game. This is a consequence of the likelihood with which some of the actions can be taken by some of the players. On the other hand, games with incomplete information are actually games with non-perfect information. In games with symmetrical information, players are informed in the same way. That is all that one player who has the most information as much as other players know. Otherwise, this is a game with asymmetric information.

The hierarchy in the information structure goes in the following order: perfect information aggregates complete and symmetrical information. Reversed does not apply. Perfect information is virtually unrealistic in the market. In a large number of cases this also applies to complete and symmetrical information. In real working conditions and business prevailing non-perfect, that is, games with incomplete, as well as games with asymmetric information. If games with nonperfect or incomplete or asymmetric information could be as much as possible translated into games with perfect, complete or symmetric information, they would create preconditions for achieving truly optimal solutions for each player. If this possibility was given to only one of the players, the outcome of market competition could easily be predicted.

The usual ways of accessing information in game theory is the belief in rationality and usefulness for players in the game, which is in line with the concept of "banning exogenous information". There are few situations where players do not have any information about the preferences of the opponents - for example, in games against nature. It is clear that without the assumption of rationality and usefulness of players, in the conditions of the prohibition of exogenous information, it would be impossible to form any kind of getting information about the payment matrix, or the expected outcome of the game. However, how one sees such belief formation depends on how one sees decision nodes-with or without appreciation of their histories. The obvious requirement for the history-insensitive view is that players ought to believe that their opponents are rational at every possible decision node. There does not seem to be an obvious requirement for the history-sensitive conception (de Bruin, 2010, p. 17).

Even in the conditions of a very strict ban of exogenous information, the appropriate information basis, on which the rational behavior of the participants in the game should be based, must be satisfied. As mentioned above, this information base should be minimally based on the collecting and processing information about behaviour of opponents in the past - at each decision-making node. This is called adaptive learning: follow the history of how other players have played in the past, and choose a strategy for the future that is a best response to the past play of others (Gints, 1999, p. 256). This would create preconditions for establishing a completely rational information flow based on rational behavior learned from past in the form of dynamic recursiveness.

Collecting data and accessing information is much easier in games in an extensive form. On the other hand, the information need in games in extensive form is far less than games in normalized form. However, from the previous two passages it can be seen that even in the theoretical considerations games in a normalized form have a greater significance than games in extensive form. Actually the normalized form is better suited for the derivation of general theorems, while the extensive form is preferable for the analysis of special cases (Von Neumann and Morgenstern, 1953, p. 85). Undoubtedly, in business and real working conditions games in normalized form are more represented. 
The conclusion of the previous analysis is that the behavior of participants in the game should be determined primarily by the information and knowledge relevant to the game in question. It was unrealistic in game theory to have designed games where players are assumed to have full knowledge of the rules and payoffs of the game. This is a serious idealization which only rarely is met in actual situations (Geckil and Anderson, 2010, p. 5).

The assumption that the players in game theory are rational has to be satisfied. However, without sufficient knowledge about the previous and, more importantly, the intended behavior of the players, it is not possible to confirm whether it is really a rational behavior. Also, information whether the threats or promises (rewards) that some players point to other players are realistic and well-founded largely determines the type of game and the behavior of the players in the game.

In game theory rationality is almost exclusively viewed in the form of matrix of payments. The matrix is the only thing that calibrates a further analysis in a certain direction in accordance with the principle of rationality. A wrong set of matrix of payment can make the whole analysis nonsense.

In conditions of insufficient information, relying on the principle of insufficient reason does not guarantee the successful implementation of any strategy. The equally plausible treatment of the emergence of each of the possible outcomes of the game is not an adequate substitute for an appropriate information base that can indicate the likely occurrence of an outcome.

Also, in the conditions of banned exogenous information, the principle of adaptive learning requires from players to monitor how other players played in games in past and on the basis of such information choose a strategy for the future, which is the best answer to the moves and strategies of other players in games in the past. Information on past behavior of player is in this case only available and without their proper collection, sorting and processing the future strategy according to which the players act should not be considered rational. What is previously said also applies to games in extensive form.

For games in normal form the information need is particularly pronounced. In the case of games without repetition, the realized profit, in accordance with the set matrix of payments, usually represents only one part of it (total profit), depending on the context in question. Full information about players can relativize the matrix of payments itself. Rationality does not necessarily imply ruthlessness and action that brings selfish, secure, and highest profit at a given moment - as it is the case in prisoner's dilemma model.

For Bayes games with non-perfect information, information about possible conditions and probabilities of their realization is crucial for the rational behavior of participants in the game. For games with a large or infinite number of repetitions information about discount rates almost completely determines the rational behaviour among players (Rasmusen, 2006, p. 113). The possibility of achieving the current profit, while sacrificing the long-term profit gained as a sum of partial profit generated in each individual game (the solution given as the perfect equilibrium) in most cases is not rational. Information about the possibilities, amount and the ways of realization potential long-term profit is often more valuable than the current profit received in the matrix of payments.

The appropriate information base, sharing of information with other players, as well as giving and collecting signals that determine the future actions and strategies of the player in question can contribute to a long-term, truly optimal solution that is essentially only rational.

\section{Proposal of the model}

The aim of the model, which will be proposed at this point, is to try to improve theoretical development and the possibility of practical application of the game theory by including the appropriate information base as support to the participants in the game. If prerequisites could 
be made that at least some forms of games bring as close as possible to games with perfect information, the goal of this model will also be fulfilled.

The graphic form of the model of international marketing research as the information basis in the game theory is attached. The verbal form follows the graphic representation.

The basis of the proposed model is the information system as support to business decisionmaking. As it is a model of international marketing research, the beginning is always on the international market, in other words the collection of data from the global environment. Such an environment is very wide, diversified and usually contains the most relevant data for a particular research. Certainly, research focus is on the collection and analysis of data related to, or could have anything to do with current or potential players and their choices in the analyzed game.

Marketing intelligence has the most important role in filtering and pointing to relevant data only. A marketing intelligence system is a set of procedures and sources that managers use to obtain everyday information about developments in the marketing environment (Kotler and Keller, 2012, p. 71). The development of global communication enables the creation of an information network at the level of a particular organizational unit (e.g., companies or other organizations) enables the creation of marketing intelligence as an information framework in strategic business decision-making. Through intelligence analysis we take collection-produced data and turn it into information, knowledge, and understanding for leaders' decision-making processes. But it is not through traditional intelligence analysis that we will come to know these things. It is through a different kind of intelligence analysis-advanced analysis-that we will come to know how to think about and subsequently use such knowledge to conduct intelligence operations to support decision-making in urban operational settings (Hall and Citrenbaum, 2010, p. 2).

The practical application of marketing intelligence is not possible without the knowledge and application of tools that are inherent and consistent with the definition of intelligence. There are three categories of business intelligence tools: tools for aiding information and knowledge discovery, tools for analyzing data to improve decision making, and tools for visualizing complex data relationships (Valacich and Schneidep, 2016, p. 249). Although each category of tools is important for marketing intelligence in the proposed model, the first category, or tools for information and knowledge discovery, is most significant. The remaining two categories of tools are fully included in the rest of the proposed model.

There are several tools, techniques, or methods that help to uncover existing data, information and knowledge in order to analyze the problem and at the initial construction of the game. Some of the most important are: method of content analysis, business negotiations, education and training, and the like. Certainly, the stated methods of access to data and information are not the only ones. Other categories could include information on websites of potential competitors or other players in game theory, purchasing data, also data obtained from: buyers, suppliers, government or supranational agencies, journalists, consultants, experts, etc. Some internal data that may be useful in this business should also be forgotten, such as: financial statements (in particular notes to the financial statements), various documents, organizational charts, instructions, procedures, policies, management of the organization, other persons with an interest in the organization and similar.

The data to be collected are determined by the research problem, that is, the relevant factors of success in a game. The information base in the game theory model is determined by the rules applicable to any game. These are the following rules: (Geckil and Anderson, 2010, p. 16)

- Players. How many players do we have in a game? Are their interests matching or conflicting? 
- Information. What information does each player possess? Do they have complete, symmetric, or perfect information regarding each other's actions and payoffs? What are the moving sequences of players?

- Actions or Strategies. What actions or strategies are the players allowed to have? What are the specifics of interaction between players? Are they allowed to communicate?

- Payoffs. What are the possible outcomes for each player? What is the utility or expected utility for each player at the end of the game for every action they are allowed to have?

Based on collected data and information it can be accessed to the initial construction of the game in a strategic or extensive form. It is an initial construction, because the data available at this moment is not complete, they are not final and have not been verified. This step is important for the theory of games, because based on the initial game analysis and data collection, information and knowledge are directed in a direction that can achieve the greatest research effects.

It would be a good idea to make a plan about further activities and thus ensure the rational disposal of resources. The planning process begins by defining the problem and determining general information needs. By analyzing the problem needs for information are reduced from the general ones to concrete and at the end, they are detailed precisely taking into account the technical possibilities and real needs of the observed organization and the concrete situation.

Conducting general information needs to specific ones could be achieved by determining the most important input variables. Although it could be concluded that it is easy to determine which basic input variables are for a particular game, this is not such case.

Previously conducted research through marketing intelligence, the initial construction of the game, as well as the expert knowledge of people working in the organization or external collaborators in the field of game theory, marketing research and information systems, should point out quite precise by which variables the research should continue. Some of the variables that might be important for some games are: the determination of the players to start or continue the game (the importance of the results of the game for players), the existence of other strategic or operational alternatives or participation in other games whose results are more important for players (when conquering or maintaining a strategic position in a particular market or product), the time required to develop a strategic game (time, or faster and better preparation for participation in the game can be decisive), material and human resources, anticipated change in the strategic the position of competitors and the like. We should not lose sight of the cultural and ideological characteristics of players, sociological and psychological characteristics, economic, legal environment and practice and customs of other competitors and the like.

These examples certainly do not exhaust the list of the most important input variables; their definition is again determined for each game and the specific situation in which each player is individually located. Answers to the following questions could help determine the basic input variables: Does everyone have the same objectives? Would other players benefit from lying to me about their strategy? Is the game fixed or variable sum? Do I want my opponent to guess my future moves? Am I better off being perceived as rational or crazy? (Miller, 2003, p. 82).

Also, the continuation of the process of collecting, processing and analyzing data, information and knowledge is not performed only by selected variables that are estimated to be able to determine the final outcome of the game, but all other data and information assumed to have an impact on the analyzed game should be collected and processed. This ensures the necessary degree of caution, which is significant in a constantly changing environment.

Data, information and knowledge represent three basic inputs into the system. Their processing and usage generate usable results that determine the strategic position in a game, and thus affect the outcome of the game. The structure of the three elements mentioned above is 
such that the data are represented the most, then information and, finally, the most scare resource, knowledge.

Data represent the basic and most common input element. These are facts that are known, partially known or completely unknown to the researcher, and whose processing and installation in a given context generates information. Researchers are surrounded on a daily basis by a large amount of data, most of which are not helpful or even pointing to the wrong track.

A questionnaire with the following content should help the organization in the process of collecting and processing data: what data is currently being collected; whether data on deviations, exceptions, etc. are collected; where and how these data are collected; where and in what form the data is stored; which application programs can be accessed by data; whether and how information is shared between applied computer programs; who and how is in charge of data reliability; who and how is in charge of data security and creation of their backups, and the like.

Data can be structured and unstructured. Unstructured are those that are not complex, categorized or sorted. Researchers estimate that $80 \%$ of all enterprise data consists of unstructured or semistructured data (Valacich and Schneidep, 2016, p. 252). In data handling, two processes need to be distinguished, their collection and processing.

Information is the second, much scarce, input element. Information is interpretation of these data. An interpretation of data always has some goal and context (Kavanagh, Thite and Johnson, 2015 , p. 67). Information represents a sufficient set of useful data with a specific tactical, operational or strategic meaning for the organization. The more strategic the information is, the more valuable they are. The harder it is to get information they are usually more valuable. It should be noted that important and valuable information is not always secret and hidden. In this context, it can be said about information transparency: Information transparency is defined as the degree of visibility and accessibility of information. In this regard, information transparency becomes one of the key features that distinguish digital exchanges from traditional markets (Zhu, 2005, p. 17).

Also, in the process of communicating messages - which are essentially information - they can move in a spectrum of secret, private or public, i.e.: message may be a "secret"(one agent receives it and the other does not know he receives it), "private" (one agent receives it, the other knows that he receives it without knowing its content and this is common knowledge) or "public" (each actor receives the message and this is common knowledge) (Walliser, 2008, p. 41). Previously said refers that information can and should, together with the data, appear as one of the components of the system's input.

The path from data to information is usually not easy and it means processing the appropriate data. Also, the information has its own "lifetime" and if it is not used within the deadline and for the needs for which they were created, they lose the category of information and switch to the lower category - the data category. Perhaps the most fundamental propositions are that the greater the task uncertainty faced by an organisation, the greater the size, and the greater the interrelatedness of units, then the greater is the amount of information to be processed (Piercy and Evans, 1983, p. 188). Because of this, information has a much higher value than the data.

Unlike information that are the goal to which researchers are striving, knowledge is a subject, that is, knowledge goes with a person, or another (artificial) intelligence, which understands the content and value of information. Knowledge is information that has been given meaning (Kavanagh, Thite and Johnson, 2015, p. 68). The meaning of the information can be given by a person, an expert in the area for which information is relevant. There are systems which are in the development process that would be able to possess and use knowledge similarly or better than the subject matter of a particular field. Consequently, what constitutes knowledge assets are all the underlying skills, routines, practices, principles, formulas, methods, heuristics, and 
intuitions, whether explicit or tacit. Explicit knowledge assets reflect knowledge that can be documented, archived, and codified, often with the help of information systems. In contrast, tacit knowledge assets reflect the processes and procedures that are located in a person's mind on how to effectively perform a particular task (Valacich and Schneidep, 2016, p. 260).

In the context of this work and the proposed model, knowledge is the ability to correctly interpret information in order to propose or make optimal decisions, or moves in game theory, either by persons - experts or artificial systems trained for such complex operations. Knowledge is the ability to understand information, form opinions, and make decisions or predictions based on information (Valacich and Schneidep, 2016, p. 48). It has already been mentioned that knowledge can be explicit and implicit.

Explicit knowledge resembles sophisticated information, and is exchanged as such. Implicit knowledge can only be dealt with by considering the entity in which it is incorporated. On the production side, it is obtained at a higher cost than information, since it is the result of hard reasoning or long experience. Moreover, knowledge is generally more effective in producing other goods than simple information is. On the consumption side, knowledge is consumed more efficiently than information, as it generates increasing returns: prior knowledge helps to build further knowledge (Walliser, 2008, p. 141).

System enters, given as data, information and knowledge, are structured so that the data represent their largest part, while the information and knowledge are the least represented. This is understandable, because marketing methods and data collection techniques mostly come up to data, while information is only a small part of their product. Knowledge is the most comfortable at this moment and is the result of knowledge that experts carry with them. The education and experience of experts from previous, similar situations certainly forms part of the knowledge that represents the entry into the system.

The central and most important part of the proposed model are people, experts for international marketing research, game theory, information systems for decision support and other similar areas. Experts dispose with collected data, information and knowledge and continue to process them in order to reach the same elements but structured otherwise. The goal is to get out of the system to make the most of knowledge and information, while the data should be at least represented.

The questionnaire with the following content should help determine the current situation regarding the human resources of the organization, as well as to enable the identification of the needs for additional staff: how the personnel involved in data collection and processing activities are organized; the number of such employees; how to report to the superior; how the work of these people fits the organization's mission; how many of these staff have been trained and qualified; is the frequent fluctuation of such employees (especially to direct competitors); what is their opinion about existing applications, information infrastructure, proposed model, and the like.

The work of the experts beside already mentioned is data collection and their processing, analysis, synthesis and interpretation. Processing of data means basic processing, but also any advanced processing that at one moment goes into data analysis. Basic data processing consists of: sorting, categorizing, tabulating, updating, etc. The goal of the data processing is to facilitate the management and records of what kind of data and in which quantity is available. It is a very important step in the research process because as advanced as technology has become, information technology still needs structured data such as a tabular format in spreadsheets or databases, to effectively process it. Yet roughly 85 percent of an organization 's data do not exist in this format, rather the data are in the form of e-mails, PowerPoint presentations, voice mails, and even meetings and conversations. Most organizations are unable to use or often even locate these "unstructured" data, and thus the potential of an invaluable resource lays unrealized (Devine, Sirinivasan and Zaman, 2004, p. 23). Some methods of data analysis require that data should be displayed and sorted in tables; otherwise their application is not possible (for example 
Goodnes of fit). The advanced processing of data includes the application of: statistical, marketing, mathematical, econometric, financial, graphic and similar methods and techniques. These methods and techniques are used for the purpose of more efficient analysis of the collected data.

An analysis implies the interpretation of complex facts into the simple elements and the understanding the relationships that exist between such elements. This is a critical step in the whole process in the proposed model, because the omission of some of the elements or lack of proper connections between them most often results in wrong information. However, the important limitation of the analysis is that the analysis does not come to a natural end, nor does it encounter a cause, it is an element that determines more than other elements than it is defined by them (Schumpeter, 2012, p. 16). The current knowledge of experts at this moment is very important and it often determines the success of a research. Without proper data analysis it is not possible to successfully perform the second critical task of the experts, or the synthesis of the analyzed data.

Under the synthesis it is assumed reassembling data which are under the analysis disassembled with the same, changed or completely new relations between them. In this work, the existing knowledge of experts, as well as their experience, ideas, creativity and the like are also expressed. By connecting appropriate data among them leads to information, the value of which should be confirmed in the market. The more impact information generated on organization and environment, its value is greater.

Synthesis is closely related to the interpretation of data. Interpretation is an assessment of the significance of the data. The corresponding estimated data take the appropriate place in the synthesis. Interpretation is also related to the synthesis result, or to information. It checks whether the analysis and synthesis is carried out in an appropriate manner, or whether the information transmits the context of the analysis and synthesis. Also, the aforementioned expert knowledge is also very evident in this case.

The task of the experts is also to maintain the connection with other information systems in the organization, such as the information system for human resources, accounting, production, management and the like. This achieves cost-effectiveness, but also partially ensures that the highly professional tasks of the experts are carried out even more professionally. By sharing resources among the information systems in the organization, a reduction in the cost of their engagement by product unit is achieved (in this case, the product is information). Increased resource utilization increases their productivity. The most suitable form of organization in this case is a network or project form. Also, by sharing resources among different information systems, especially the best quality resources, better product quality is achieved.

As the focus of the proposed model is on experts their value grows. Investing in their additional training will increase the knowledge and experience they have at their disposal. Also, experts should have high creativity, the ability to produce ideas and the skills to find new facts and knowledge. This is especially important when synthesizing and creating information. Few of these key characteristics of the experts determine the success of the proposed model.

In addition to the aforementioned, the application of the proposed model requires some other resources, namely: business networking, databases, appropriate computer programs (software), hardware, established procedures and the like. Business networking is an unlimited possibility of accessing the Internet at the appropriate data transfer speed, then the possibility of accessing intranet networks, as well as the possibility of accessing some local or regional networks (library, branch network, etc.). The ability to access databases is also a very important resource. Databases are mainly in electronic form and are accessed via the Internet or some local networks. When we talk about the classic concept of marketing research, we need to underline the fact that the Internet and data bases available via the Internet (but only as a source of secondary data) and various software applications for data processing are used for these 
marketing researches. However, that is a far lower level of application of information technology in marketing research in comparison with the online concept (Hanić and Čivić, 2017).

There are also some older databases that are not in electronic, but in material form. Access to such a database is important, but it is not critical. It would be good if there are established working procedures, exchanges, behaviors, etc. which can direct the work and behavior in the application of the proposed model, as well as to ensure the smooth functioning and flow of data and information.

The questionnaire with the following content should help determine the current technical condition of the organization, as well as to enable identification of the need for additional technique: what hardware make the existing IT infrastructure; what basic and applied computer programs are currently being used; whether the infrastructure has become obsolete; is there any overclocking of the system; which network infrastructure is currently being used; whether the IT infrastructure is decentralized; whether some parts of the information infrastructure are leased; in which ownership is the IT infrastructure and the like.

Analyzing the answers to the previous questions, information about existing and currently available resources should be provided, i.e. how well they serve the organization. Also, the answers to the questions will also indicate the segments that should be changed and/or improved.

The purpose of applying the proposed model is the exits from the system in the form of data, information and knowledge. The result of the described process of the proposed model should be the values in which the data are the least represented, while the most common are information and knowledge. It is certainly not possible to avoid data completely as a result of work; it's not even the goal. The data can help in decision making, however, their greatest value is in re-entering the system in the next iteration using dynamic recursiveness.

Information is the most important component that influences decision-making. They are dynamically focused, that is, their goal is the effect and to make some change. Their quality influences the decision, and hence the future of the organization. Information should be the most significant result of the proposed model. In addition to information, the knowledge that the experts acquire while working on the process in the proposed model are also the most important product of the model. The value of the mentioned knowledge could be read in the possibility of interpreting the aforementioned information, as well as the possibility of applying this knowledge in the next iteration in the proposed model. The result is continuous improvement and raising the quality of the proposed model.

The problem with which each of the information systems or other forms of data collection and processing often meets is the exit from the system in the form of an excessive amount of data and information. Knowledge is least represented in this case. An excessive amount of data and information suffers to the whole system and diminishes its effectiveness. Information is often produced without an appropriate goal, or the goal is to create as much of the necessary and unnecessary data and information as possible. Uncontrolled information generation is of no use to an organization (Devine, Sirinivasan and Zaman, 2004, p. 28). This is called redundancy, capturing the same data more than once leads to data redundancy and inconsistency. Information systems have limited collection, processing, and data storage capacity. Data redundancy overloads facilities and reduces the overall efficiency of the system. Inconsistency among redundant data elements can result in inappropriate actions and bad decisions (Hall, 2011, p. 12).

Certainly the goal is to reduce or completely eliminate redundancy. Although this is not an easy task, experts should, during the work on data collection, processing and accessing information and also by gaining knowledge and experience (they are not decision makers), recognize what information is relevant. By presenting only relevant information, redundancy 
will be reduced. The most relevant information, which arises in the process of work in the proposed model, should be archived in databases and preserved for eventual later application.

Based on the relevant information, as well as on the basis of the acquired knowledge and experience, in cooperation with decision makers, reconstruction of the game set at the beginning of the described process should be carried out. The new knowledge gained in the application process of the proposed model should, in most cases, provide a proper setting of the game in a strategic and / or extensive form. The difference with respect to the original construction of the game should reflect the value and quality of the entire process in the proposed model. Greater security reflected in the realistic setting of the game and, based on that, making better decisions or strategic moves in the game, is a motive for the reconstruction of the game. Although the responsibility at this point in the whole process may be the biggest one, it should be kept in mind that this is not the last phase before making the final decision. The reconstructed game should be tested before the final setting of the game and making a decision.

It is possible to test different alternative scenarios, as well as the sensitivity of the system output and reconstructed games. Result of system output is usually the large amount of data, information and knowledge, they can be contradictory to each other, which can sometimes result in different ways how to reconstruct the game. It would be good for each of the alternatives, in cooperation with the decision makers, to test separately.

To test a game means to put it in the context of a real market situation, taking into account some less likely situations. By testing, some actions of the players in the game are developed to certain iteration in the future. The player's behavior is checked based on the information collected and conclusion drawn on that basis if the reconstructed game is valid. Although it is not easy task to simulate the real situation of players' behavior in a game, this step is also important, because it can indicate the quality of the work done so far.

Based on the results of the performed game tests (or several alternative games), the final game setting is performed according to the most important elements, such as: payment matrix, information on the player's rational behavior, history of player's behavior and gameplay, probability of choice assigned to each of the possible strategic alternatives for each of the players in the game, to which iteration could repeat the game, and other elements that may be relevant in the context of each particular game.

Making a decision is one of the results of the work of the proposed model; the second one is, due to the constant change in the global environment, the restart of the process, this time anticipating the results of already made own decisions. In real life, most of the games are played more than once. Play may unfold differently with a sequential game; that is where the players play the game more than once consecutively. We call this type of game dynamic. Repeated games are dynamic. An example of a real life dynamic game would be one where firms set prices periodically (Geckil and Anderson, 2010, p. 30). The proposed model has the characteristics of a dynamic model, but its dynamism is not the result of a simple reboot, but rather a result of established dynamic recursiveness.

\section{CONCLUSION}

Greater practical application of game theory, not only in very specific conditions, or when dealing with isolated problems such as: nuclear wars, major political, economic or social conflicts, sanctions, and so on but its application in addressing problems that are more often encountered in everyday business, should be a significant preoccupation for those who intend to give their contribution to development and practical application of game theory.

The greater representation and usability of game theory in business decision-making in conditions of globalized business can provide an adequately designed model of international marketing research in the form of an information decision support system for business. The model proposed in this paper could largely remove or reduce the deficiencies in game theory, 
and make the game theory one of the most important tools in the hands of the business or marketing decision maker. The development of the appropriate information-based decisionmaking in game theory is the greatest contribution of this paper.

The information flow from the international market is the most important information basis in the conditions of globalized business. Data and information that are not verified on the international market have a major disadvantage because they carry the risk of incomplete coverage, obscurity or inadequacy. Only the global environment in present and future business represents a final information instance.

International marketing research and game theory, two largely unconnected and mutually distant disciplines, are by the proposed model somewhat closer. Linking of the two disciples makes reduction of entropy in business or marketing decision-making. Proposed model is one of the ways of connecting the two disciplines and providing information support in game theory. With this work the mentioned possibilities are not exhausted.

Certainly the possibility of further improvement of the proposed model remains, prioritizing the establishment of a dynamic recursive linkage of the model output with the re-entry into the model, respecting the changes that the decisions made can have on the behavior of the other players. The most appropriate form of the proposed dynamic recursiveness could be a neural network. Also, there is a possibility of mathematical programming of same parts in the proposed model, as well as the possibility of developing appropriate forms of testing reconstructed games based on available data, information and knowledge. 


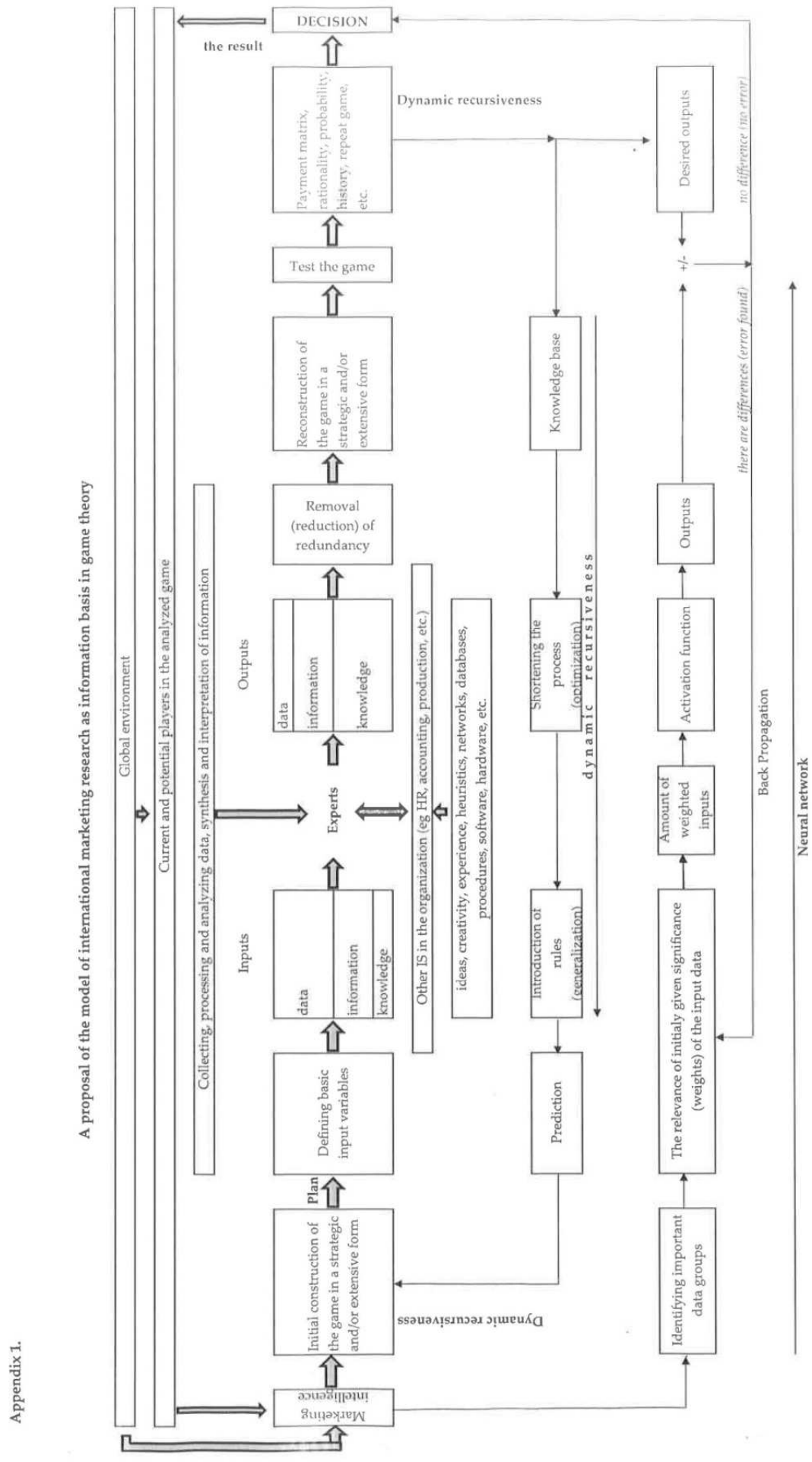




\section{REFERENCES}

Bryman, Alan, and Emma Bell. 2003. Business Research Methods. Oxford: Oxford University Press.

Chatterjee, Kalyan, and Gary L. Lilien. 1986. "Game theory in marketing science, Uses and limitations", International Journal of Research in Marketing, 3: 79-93.

Chowdrey, N. 2014. "Playing 'game theory' as a marketing tool", Marketing, December 4. http://www.marketingmagazine.co.uk/article/1309753/playing-game-theory-marketingtool.

de Bruin, Boudewijn. 2010. Explaining Games - The Epistemic Programme in Game Theory. Dordrecht: Springer Science+Business Media B.V.

Devine, Patrick W., Sirinivasan C. A. and Maliha Zaman S. 2004. "Importance of Data in Decision-Making" In Business Intelligence Techniques, a Perspective from Accounting and Finance, ed. Murugan Anandarajan, Asokan Anandarajan and Cadambi A. Srinivasan, 19-39. Berlin Heidelberg: Springer-Verlag GmbH.

Gaus, Džerald. 2012. O filozofiji, politici I ekonomiji. Beograd: JP Službeni glasnik.

Geckil, Ilhan K., and Patrick Anderson L. 2010. Applied Game Theory and Strategic Behavior. Boca Raton: Chapman and Hall/CRC.

Gibbons, Robert. 1992. Game Theory for Applied Economists. New Jersey: Princeton University Press.

Gints, Herbert. 1999. Game Theory Evolving. New Jersey: Princeton University Press.

Hall, Wayne M., and Gary Citrenbaum. 2010. Intelligence Analysis: How To Think In Complex Environments. Santa Barbara: ABC-CLIO, LLC.

Hall, James A. 2011. Accounting Information Systems. Mason: Cengage Learning.

Hanić, Hasan, and Čivić, Beriz. 2017. "Specificities of Online Concept in Comparision with a Classic Concept of Marketing Research", Economic Analysis, v. 42, n. 1-2, p. 43-52, http://www.library.ien.bg.ac.rs/index.php/ea/article/view/120>.

Hargreaves, Shaun, and Yanis Varoufakis. 1995. Game Theory, A Critical Introduction. London and New York: Routledge.

Kavanagh, Michael, J., Mohan Thite, and Richard Johnson D. 2015. Human resource information systems: basics, applications, and future directions. Thousand Oaks: SAGE Publications Inc.

Kevin, Zhu. 2005. "Information Transparency Hypothesis: Economic Implications of Information Transparency in Electronic Markets" In Advances in the economics of information systems. ed. Tomak, K. 15-42. Hershey: Idea Group Publishing Inc.

Kotler, Philip and Kevin Lane Keller. 2012. Marketing Management. New Jersey: Pearson Education Inc.

Miller, James D. 2003. Game Theory At Work - How to Use Game Theory to Outthink and Outmaneuver Your Competition. New York: McGraw-Hill Education.

Peng, Mike W. 2011. Global business. Cincinnati: South-Western Cengage Learning.

Piercy, Nigel, and Martin Evans. 1983. Managing Marketing Information. New York: Routledge Taylor \& Francis Group.

Rapoport, Anatol. 1966. Two-Person Game Theory - The Essential Ideas. Michigan: The University of Michigan Press.

Rasmusen, Eric. 2006. Games and Information, An Introduction to Game Theory. Malden: Blackwell publishing.

Salvatore, Dominick. 2013. International Economics. New Jersey: John Wiley and Sons Inc.

Stebbing, Susan L. 1961. A Modern Introduction to Logic. New York: Harper \& Row.

Stiglitz, Joseph E. and Carl E. Walsh. 2006. Economics. New York: W.W. Norton \& Company.

Valacich, Joseph, and Christoph Schneidep. 2016. Information Systems Today: Managing in the Digital World. New Jersey: Pearson Education Ltd. 
Von Neumann, John, and Oskar Morgenstern. 1953. Theory of Games and Economic Behavior. Princeton, New Jersey: Princeton University Press.

Walliser, Bernard. 2008. Cognitive Economics. Berlin Heidelberg: Springer-Verlag.

Webb, James N. 2007. Game Theory - Decisions, Interaction and Evolution. London: SpringerVerlag.

Šumpeter, Jozef. 2012. Teorija privrednog razvoja. Beograd: JP Službeni glasnik.

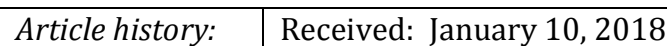

Accepted: May 23, 2017 